\title{
Guide Vane with Current Plate to Improve Efficiency of Cross Flow Turbine
}

\author{
Kiyoshi Kokubu ${ }^{1}$, Toshiaki Kanemoto ${ }^{2}$, Keisuke Yamasaki ${ }^{1}$ \\ ${ }^{1}$ Graduate School of Engineering, Kyushu Institute of Technology, Kitakyushu, Japan \\ ${ }^{2}$ Faculty of Engineering, Kyushu Institute of Technology, Kitakyushu, Japan \\ Email: kiyoshi-kokubu@tanasui.co.jp
}

Received June 3, 2013; accepted June 10, 2013; accepted June 17, 2013

Copyright (C) 2013 Kiyoshi Kokubu et al. This is an open access article distributed under the Creative Commons Attribution License, which permits unrestricted use, distribution, and reproduction in any medium, provided the original work is properly cited.

\begin{abstract}
To get the sustainable society, the hydropower with not only the large but also the small/mini/micro capacities has been paid attention to in the power generation. The cross flow turbine can work effectively at the comparatively low head and/or low discharge, then the runner and the turbine profile has been optimizing. In this paper, the model turbine was prepared in accordance with the traditional design, and the performance and the flow condition were investigated experimentally at the various operating conditions. The hydraulic efficiency is doubtlessly maximal while the guide vane is at the normal/design position, and deteriorates in the lower discharges adjusted by the guide vane. Such deteriorations are brought from the unacceptable flow conditions in the inlet nozzle. To improve the efficiency dramatically in the lower discharge, the guide vane installed in the inlet nozzle was equipped with the current plate, and the fruitful effects of the plate on the efficiency were confirmed experimentally.
\end{abstract}

Keywords: Hydraulic Turbine; Cross Flow Turbine; Guide Vane; Inlet Nozzle; Hydraulic Efficiency; Discharge

\section{Introduction}

It is desired to exploit the renewable energies, and the hydro resources, such as small/mini/micro-scaled rivers, agricultural/industrial channel/drain and so on, are expected to play a great role in the power generation [1]. It is very important, for meeting such needs, to reduce the initial cost of the power plant, since the plant does not generate much electricity in comparison with the largescaled power plant [2]. The cross flow turbine is assembled with few components, and can work effectively at the comparatively low head and/or low discharge in the onshore and offshore without nature disruptions. These advantages have been demonstrated in many researches, moreover, the turbine profile has been optimizing [2-4]. Nevertheless, the hydraulic efficiency of the cross flow turbine is still lower than the efficiency of the turbines such as the bulb/Francis/Pelton types used widely [5]. The supposable reasons for the lower efficiency are as follows: 1) the flow crossing in the runner may contact the main shaft at the partial load; 2) the flow direction re-entering to the runner at the inner diameter does not meet the blade angle; 3 ) the guide vane makes the flow condition unacceptable for the runner blade in the low discharge. To address these points, the installation of the passage in the runner has been proposed to guide the flow direction [6,7]. On the contrary, this paper proposes to modify the guide vane profile in response to the discharge.

\section{Preparations to Improve Efficiency}

\subsection{Model Cross Flow Turbine in Tradition}

The inlet nozzle and the runner profiles affect directly the performance of the cross-flow turbine, and are prepared for house works in accordance with the traditional design [8] to understand the factors lowing the efficiency.

\subsubsection{Inlet Nozzle}

The inlet nozzle gives the angular momentum to the runner, and it is desirable to give the same momentum in the peripheral/tangential direction. Besides, the flow angle at the nozzle outlet, measured from the circumferential direction, should be smaller in the same way as the jet flow of Pelton turbine. Taking the material strength and the fabrication into account, the angle was set at $\alpha_{1}=$ 17 degrees on the casing walls and the concave surface of the guide vane, as shown in Figure 1. The opening angle of the nozzle outlet is 109 degrees in accordance 


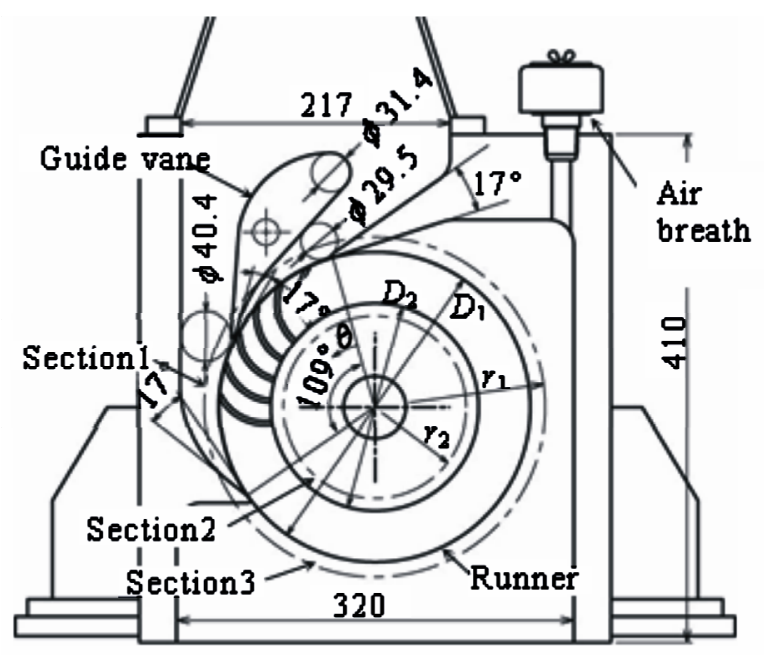

Figure 1. Model cross flow turbine.

with reference [9]. The spiral type streamline may give the same momentum in the circumferential direction, but that makes the turbine size very large. Then, the most of the walls are straight and the walls close to the outlet of the nozzle are curved with $\alpha_{1}=17$ degrees.

The cross sectional areas along the concave and the convex surfaces of the guide vane change gradually and smoothly in the stream-wise, where the minimum width is $40.4 \mathrm{~mm}$ at the convex side and $29.5 \mathrm{~mm}$ at the concave side while the guide vane opening is at the nor$\mathrm{mal} /$ design position $(\mathrm{GO}=100 \%)$ shown in Figure 1 . The guide vane opening is adjusted by the rotation around the stem, and the passages can be closed $(\mathrm{GO}=$ 0 ) at the leading and the trailing edges.

\subsubsection{Runner}

The blade angle at the outer diameter of the runner was designed as follows. The rotational velocity $u_{1}$ at the outer diameter of the runner is given by

$$
u_{1}=\pi D_{1} n / 60=k v_{1}=k(2 g H)^{1 / 2}
$$

where $D_{1}$ is the outer diameter of the runner, $n$ is the rotational speed, $k=0.45$ is the velocity coefficient and brought from the coefficient of Pelton turbine [10], $H$ is the effective head and the absolute velocity $v_{1}$ is given by $(2 g H)^{1 / 2}$. Then, the blade angle $\beta_{1}$ given by Equation (2) without the incidence angle, namely the relative flow angle, is derived from the $v_{1} \sin \alpha_{1}=\left(v_{1} \cos \alpha_{1}-u_{1}\right) \tan \alpha_{1}$ (see Figure 2), Equation (1) and $\alpha_{1}=17$ degrees.

$$
b_{1}=\tan ^{-1}\left[\sin a_{1} /\left(\cos a_{1}-k\right)\right]=30 \text { degrees }
$$

This angle is reasonable as well known [8].

Assuming the number of blades is infinite and the flow is in the ideal condition without the gravitational effects, the relative velocity component at Section $3\left(w_{3}\right)$ is the

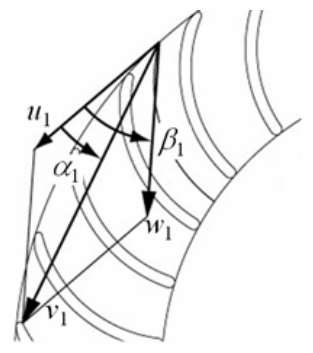

At Section 1

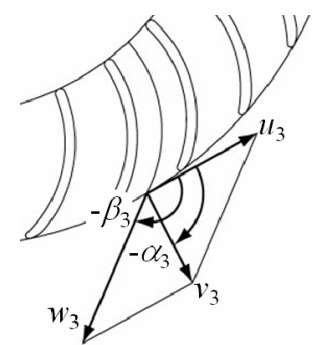

At Section 3

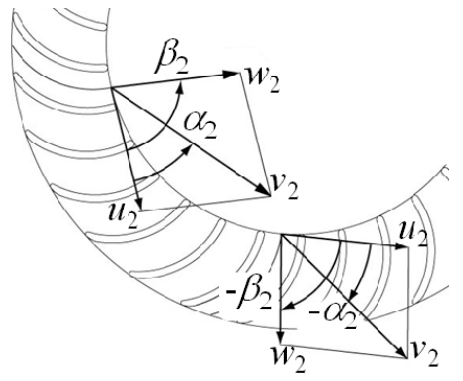

At Section 2

Figure 2. Velocity triangles.

same as the velocity at Section $1\left(w_{1}\right)$, but the flow direction turns to 180 degrees. Then, the flow conditions with $\alpha_{1}=30^{\circ}, \beta_{1}=17^{\circ}$ and $k=0.45$ at Section 1 give the flow angle $\alpha_{3}=-100$ degrees at Section 3. The angle $\alpha_{3}$ is accepted taking account of Reference [3], though $\alpha_{3}$ deviating from the radial direction makes the discharge loss increase more or less.

The main shaft installed in the runner may contribute to increase the rotational torque and deteriorate the flow condition at Section 2, while the flow crossing in the runner contacts with the main shaft. The flow pattern crossing in the runner is determined with the blade angle at the inner diameter of the runner and the outlet position of the inlet nozzle. Then, the blade angle $\beta_{2}$ was set at 87 degrees as recommended by Reference [3], and the outlet position was set as shown in Figure 1 so as the flow crossing in the runner does not contact with the imaged shaft of 0.18 times as small as the inner diameter of the runner.

\subsection{Model Setup and Experiments}

Model cross flow turbine shown in Figure 1 is composed of the inlet nozzle with the guide vane, the runner, and the casing with the air breath. The runner, which was designed at $N_{11}=n D_{1} / H^{1 / 2}=41.4 \mathrm{~m}, \min ^{-1}$, has the outer diameter of $D_{1}=250 \mathrm{~mm}$, the inner diameter of $D_{2}=167$ $\mathrm{mm}$, and 30 blades formed with the single arc camber of $3 \mathrm{~mm}$ thickness and the height of $B=16 \mathrm{~mm}$. The runner has not the front shroud, and the clearance between the blade tip and the front casing is $1 \mathrm{~mm}$. Besides, the runner has not the main shaft and is the overhang type. The model has not the draft tube, that is, Section 3 is exposed 
to the atmospheric air.

In the experiments, the turbine head $H$ and the discharge $Q$ were given by the booster pumping system stood at the upstream, where $H$ was defined by the head at the center of the main shaft and estimated with the static and the dynamic pressures at the turbine inlet, and $Q$ was measured by the orifice. The discharge $Q$ is adjusted by the guide vane. In this paper, the guide vane opening (GO) is defined as the percentage of the adjusting/rotating angle $(\mathrm{GO})$ from $\mathrm{GO}=100 \%$ while the vane is fully open (at the original/design position shown in Figure 1) to $\mathrm{GO}=0 \%$ while the passage is shut off by the guide vane [3]. The runner speed is adjusted by the inverter system with the regenerative braking circuit, and is measured accompanying with the rotational torque.

The hydraulic efficiency $\eta$ and the shaft power $P$ were evaluated without the power losses by the sealing and the bearing. The flow around the runner, at the middle blade height of Sections 1, 2 and 3 is steadily measured with the 3 hole Pitot tube composed of the wiry tube (the outer diameter of $1 \mathrm{~mm}$ ). Figure 3 shows the velocity distribution in the width direction at $\theta=2^{\circ}$ of Section 1 , where $\theta$ is the central angle measured from the upper edge of the inlet nozzle (Figure 1), and $z / z_{0}$ is the dimensionless distance from the front casing. It may be proved that the boundary layers on the end walls scarcely affect the runner performance and the flow conditions.

\subsection{Turbine Performances}

Figure 4 shows the turbine performances, where $Q_{11}$ is the unit discharge $\left[=Q /\left(B D_{1} H^{1 / 2}\right)\right], P_{11}$ is the unit output $\left[=P /\left(B D_{1} H^{3 / 2}\right)\right], \eta$ is the hydraulic efficiency $[=P /(\rho g Q H)]$, and $\eta_{\max }$ is the maximum hydraulic efficiency at $N_{11}=$ $40.7 \mathrm{~m}, \mathrm{~min}^{-1}$ with $\mathrm{GO}=100 \%$ which is in proximity close to $41.4 \mathrm{~m}, \mathrm{~min}^{-1}$ at the design stage. The maximum output and hydraulic efficiency are at about $N_{11}=40.7 \mathrm{~m}$, $\min ^{-1}$ for GO $=100 \%$. The output and the efficiency deteriorate and $N_{11}$ giving the maximum $\eta \eta_{\max }$ and $P_{11}$ is slower, with the decrease of the guide vane opening (GO), namely the unit discharge $Q_{11}$. Besides, the unit discharge $Q_{11}$ increases slightly as $N_{11}$ is slow, and above characteristics has been well known [8].

The hydraulic efficiency deteriorates as the guide vane opening GO decreases, because the profile of the inlet nozzle is optimized at $\mathrm{GO}=100 \%$ in the design stage. The experiment in house shows that the deterioration of the efficiency is noticeable at GO smaller than $60 \%$.

\subsection{Flow Conditions}

\subsubsection{Flow Condition at Section 1}

The flow conditions at Section 1 are shown in Figure 5, where the flow angles $\alpha_{1}, \beta_{1}$, and the velocity $v_{1}$ are in Figure 2. The relative flow angle $\beta_{1}$ is in close to the

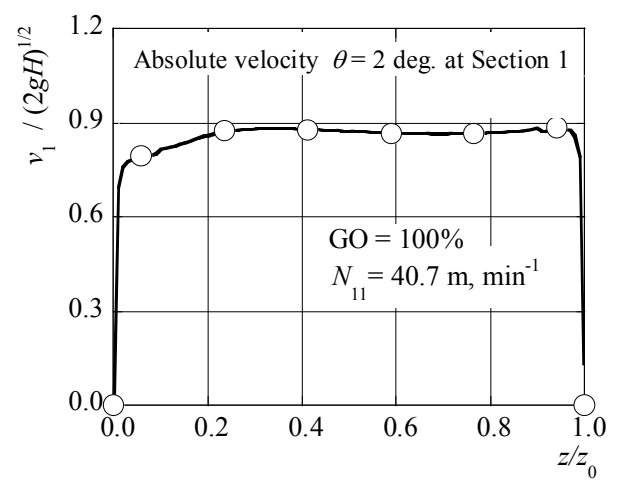

Figure 3. Velocity distribution in the inlet nozzle width at Section 1.

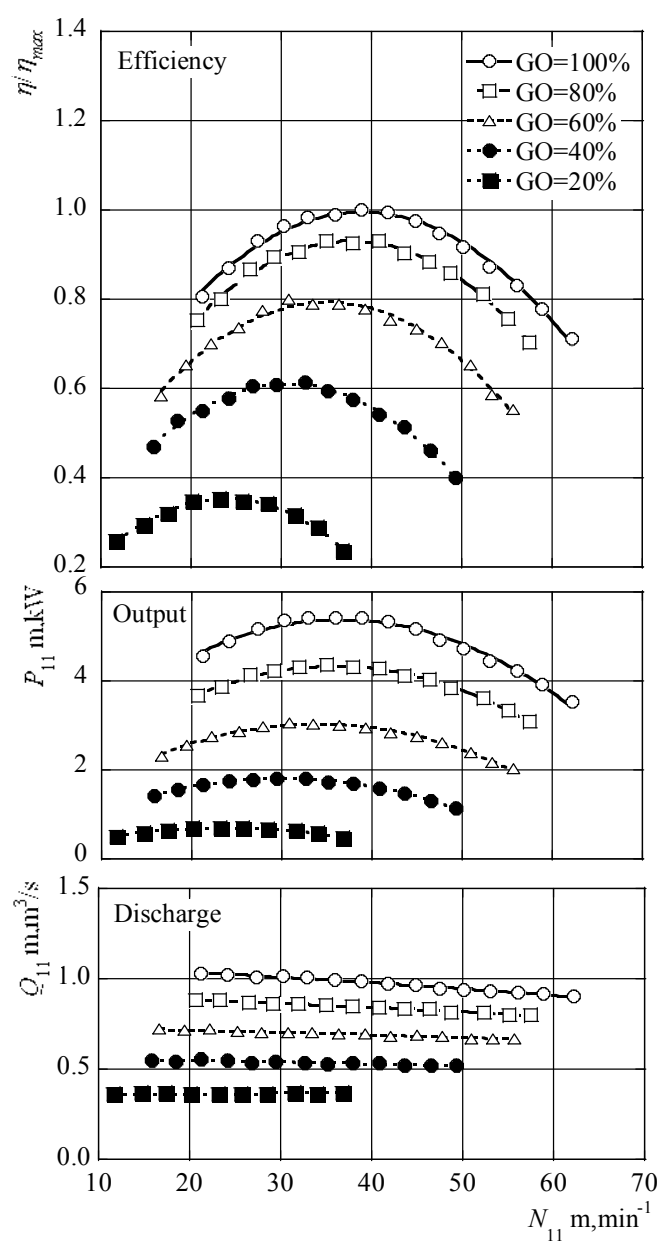

Figure 4. Turbine performances.

shock less condition without the incidence angle for the blade at the outer diameter of the runner, namely the zero incidence angle at GO $=100 \%$ (Figure 5(b)), as expected at the design stage. At $\mathrm{GO}=20 \%$, the flow along the concave/right surface of the guide vane runs outward ( 0 degree $<\theta<55$ degrees in Figure 5(a)), and runs inside accompanying with the flow along the convex/left surface of the guide vane in the region larger 


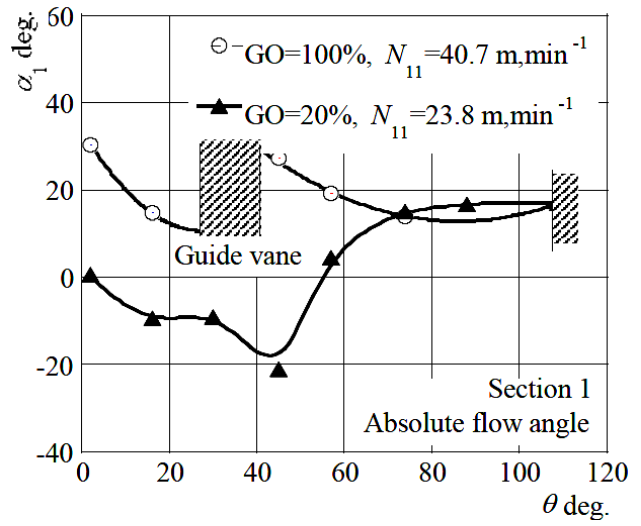

(a)

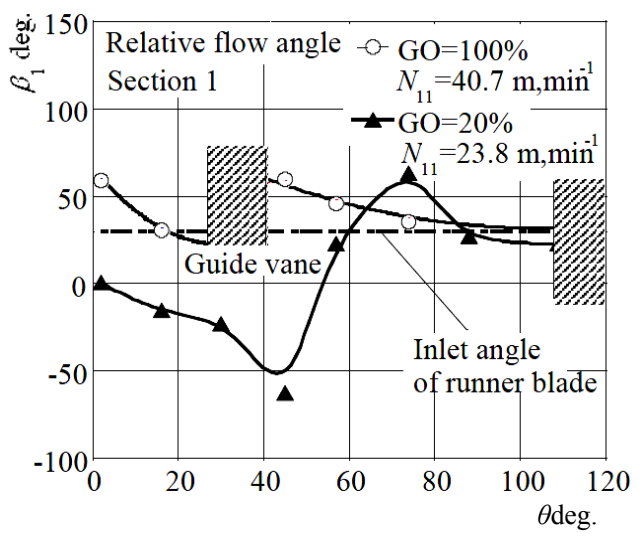

(b)

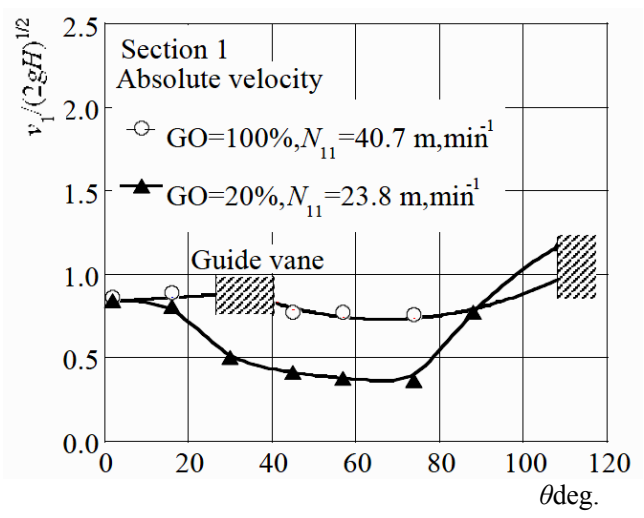

(c)

Figure 5. Flow conditions at Section 1: (a) Absolute flow angle; (b) Relative flow angle; (c) Absolute velocity.

than $\theta=55$ degrees in Figure 5(a). That is, the runner works effectively in the lower casing wall (large $\theta$ ) at the small GO. The flow may contribute to break more or less the runner rotation near $\theta=70$ degrees, because the flow is very slow with the comparatively large $\beta_{1}$ (Figure 5(b) and (c)).

It is supposable that such flow conditions make the runner work, namely the hydraulic efficiency, deteriorate in the small guide vane opening (low discharge). Thus, it is expected to improve the flow condition through the passage surrounded by the concave/right surface of the guide vane in the small opening.

\subsubsection{Flow Condition at Section 2}

Figure 6 shows the flow angles at Section 2, where the flow angles are also given in Figure $\mathbf{2}$ and the boundary between the flow crossing in the runner and the ambient air was measured with the flow visualization. Section 2 has the flow discharging from the runner blade in $\alpha_{2}>0$ degree (discharging region) and the flow re-attacking to the runner blade in $\alpha_{2}<0$ degree (attacking region), where $\theta$ giving $\alpha_{2}=0$ degree is the border to separate those two regions. The discharging region moves to the large central angle $\theta$ at the small guide vane opening, but the flow angle against $\theta$ is scarcely affected by the guide vane opening, because the discharging flow direction depends on the blade angle.

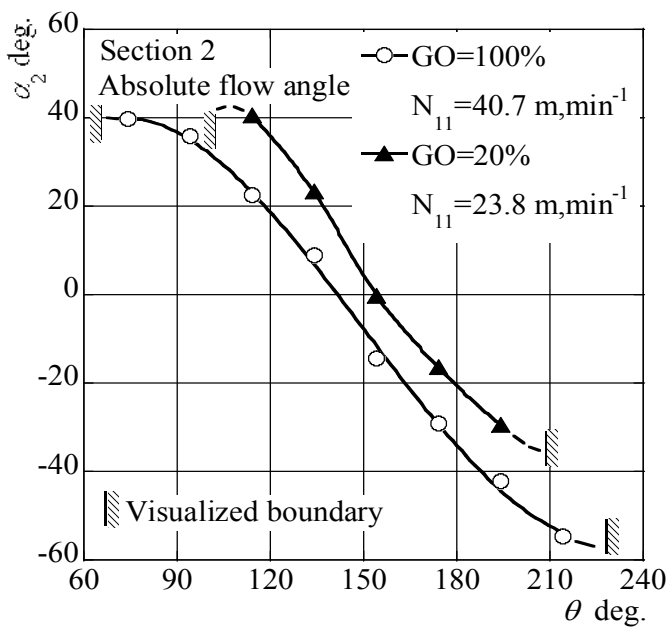

(a)

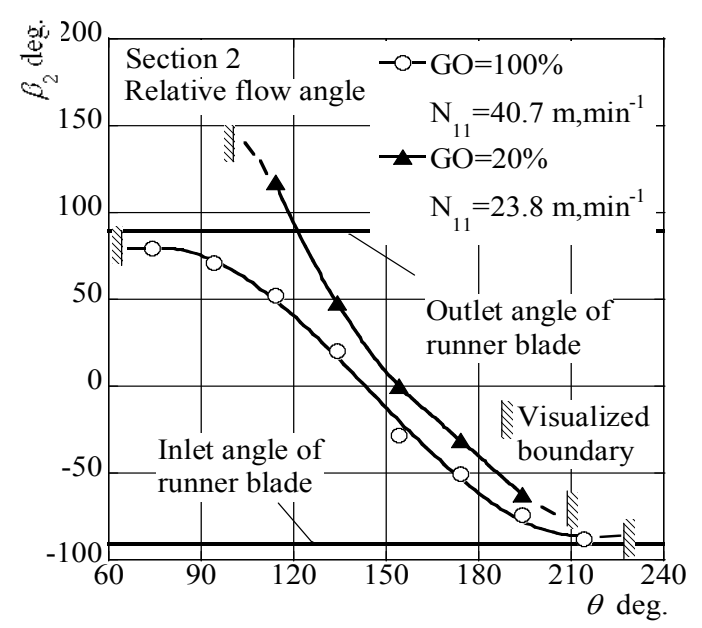

(b)

Figure 6. Flow angles at Section 2: (a) Absolute flow angle; (b) Relative flow angle. 
The relative flow angle changes in the tangential direction and does not meet the blade angle, as shown Figure 6(b). To rectify the flow direction and reduce the shock loss, the flow passage was installed in the runner $[6,7]$. The authors, however, cannot improve the hydraulic efficiency by such passages, in house experiments [11].

\subsubsection{Flow Condition at Section 3}

Figure 7 shows the absolute flow angle at Section 3, which has the flow discharging not to the inside but to the outside of the runner (Section 1-3) and the flow after crossing in the runner inside (Section 1-3), where $\alpha_{3}$ is given in Figure 2. Both flows are separated at $\theta=187$ degrees for $\mathrm{GO}=100 \%$, and $\theta=203$ degrees for $\mathrm{GO}=$ $20 \%$. The discharging flow angle is larger than $\alpha_{3}=-90$ degrees and may make the discharging loss increase at $\mathrm{GO}=20 \%$, though the optimum angle is $\alpha_{3}=-90 \mathrm{de}-$ grees.

\subsubsection{Analysis of Output}

Figure 8 shows the streamlines obtained experimentally from the absolute flow, where these are at the $N_{11}$ giving the maximum hydraulic efficiency, respectively, S2 - S9 were estimated with the flow quantitatively measured at Sections, S1 and S10 were estimated from the flow visualization. Figure 9 shows the theoretical power fraction estimated from the angular momentum measured

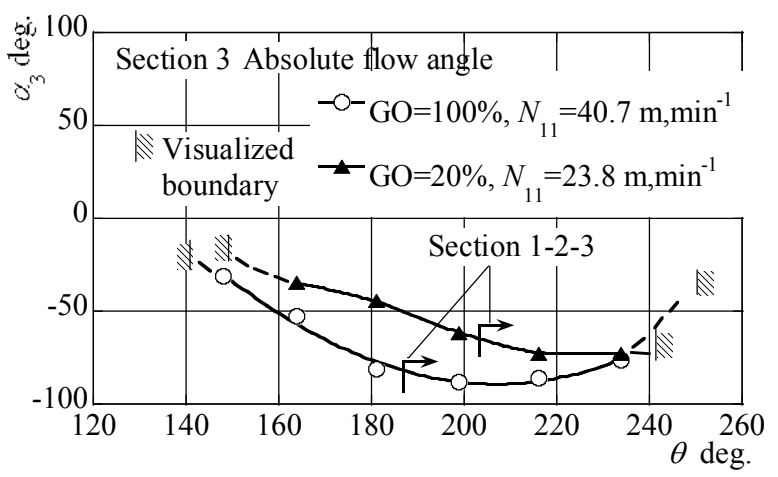

Figure 7. Absolute flow angle at Section 3.

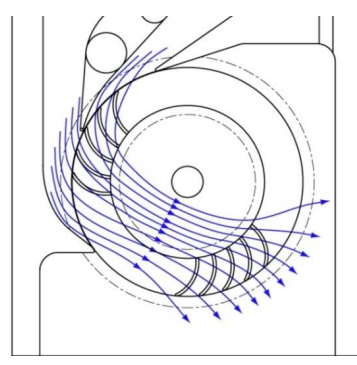

(a)

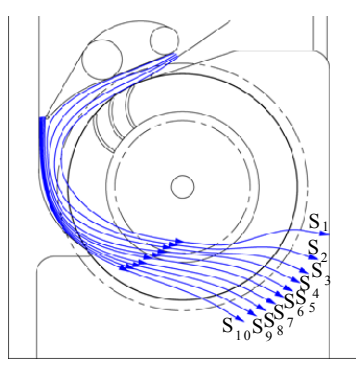

(b)
Figure 8. Streamlines: (a) GO $=\mathbf{1 0 0} \%\left(\mathrm{~N}_{11}=40.7 \mathrm{~m}, \mathrm{~min}^{-1}\right)$; (b) GO $=20 \%\left(\mathrm{~N}_{11}=23.8 \mathrm{~m}, \mathrm{~min}^{-1}\right)$. on each streamline, where the fraction is $\varepsilon=$ the power on each streamline: $\left.P_{S T}\right) /$ the summation of $\left.P_{S T}: \Sigma P_{S T}\right)$. At the small guide vane opening $\mathrm{GO}=20 \%$ (Figures 8 (b) and 9(b)), the power fraction $\varepsilon$ through Section 1-3 increases, that is, the fraction through Section 1-2-3, especially $1-2$, decrease obviously. On the contrary, the flow through Section 1-2 contributes to increase the power at the large guide vane opening (Figures 8(a) and 9(a)). These results and Figure 5 suggest that it is very important to improve the flow condition in the smaller central angle $\theta$ at Section 1 while the guide vane opening is small.

\section{Improving Efficiency in Low Discharge}

\subsection{Guide Vane Equipping with Current Plate}

In response to the above suggestion, the guide vane equipped with the current plate of the single arc as shown in Figure 10. Current Plate $A$ is attached to the concave surface of the guide vane at $\theta=4$ degrees of $\mathrm{GO}=60 \%$ and comes at the outer diameter of the runner with the clearance of $1 \mathrm{~mm}$ on $\theta=31$ degrees, where the plate angle at the trailing edge coincides with the relative flow angle $\beta_{1}$ while operating at the maximum efficiency of $\mathrm{GO}=20 \%$. In the same manner, Current Plate B is attached to the guide vane at $\theta=17$ degrees and comes at the runner outside on $\theta=43$ degrees. In the practical use, the current plate may be made of the shape-memory alloy plates.
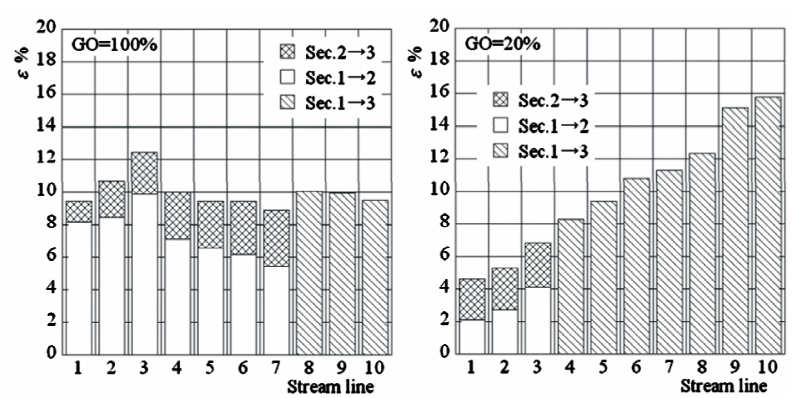

Figure 9. Power fraction between streamlines: (a) GO = $100 \%\left(\mathrm{~N}_{11}=40.7 \mathrm{~m}, \mathrm{~min}^{-1}\right)$; (b) GO $=20 \%\left(\mathrm{~N}_{11}=23.8 \mathrm{~m}\right.$, min $\left.^{-1}\right)$.

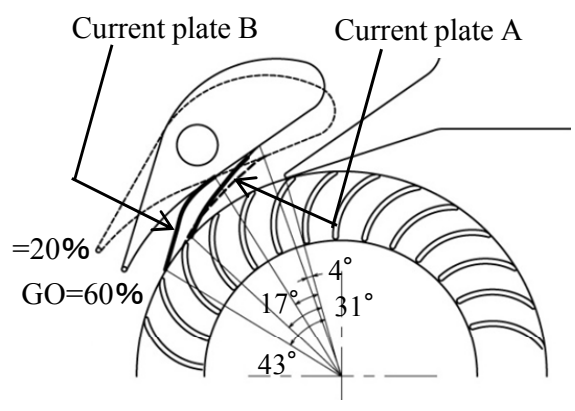

Figure 10. Current plates. 


\subsection{Improvement of Hydraulic Efficiency}

Figure 11 shows the effect of current plates on the hydraulic efficiency, where $\eta_{\text {Pmax }}$ and $\eta_{\text {Gmax }}$ are the maximum hydraulic efficiencies with the plate and without the plate at each guide vane opening (GO). Current Plate A is effective to improve the efficiency drastically in GO smaller than 55\%. Current Plate B also improves slightly the efficiency in the region of $40 \%<\mathrm{GO}<60 \%$, but the plate is ineffective in total to improve efficiency. One reason may be that the flow runs outward more or less because the plate is at more downstream than Current Plate $\mathrm{A}$ and the plate has the large turning angle. Besides, it is not desired to improve the efficiency by the plate attached to the surface at the far upstream of Current Plate A, because of the extreme narrow passage.

Figure 11 also shows the unit discharge $Q_{11 \text { opt }}$ giving the efficiency $\eta_{\mathrm{Pmax}} / \eta_{\text {Gmax }}$. The discharge is slightly affected by the current plates and is almost proportional to the guide vane opening GO.

Figure 12 shows the hydraulic efficiency with Current Plate A against the unit rotational speed $N_{11}$. The distribution of the efficiency scarcely affected by the current plate and the guide vane opening, but the hydraulic efficiency is notably improved especially in smaller guide vane opening.

\subsection{Flow Conditions}

Figure 13 shows the effect of the plate on the flow condition at Section 1, while operating at the highest efficiency of $\mathrm{GO}=20 \%$. The flow runs in the radial direction in the region of 15 degrees $<\theta<60$ degrees surrounded by the back surface of the plate and the concave surface of the guide vane, but the flow scarcely affects

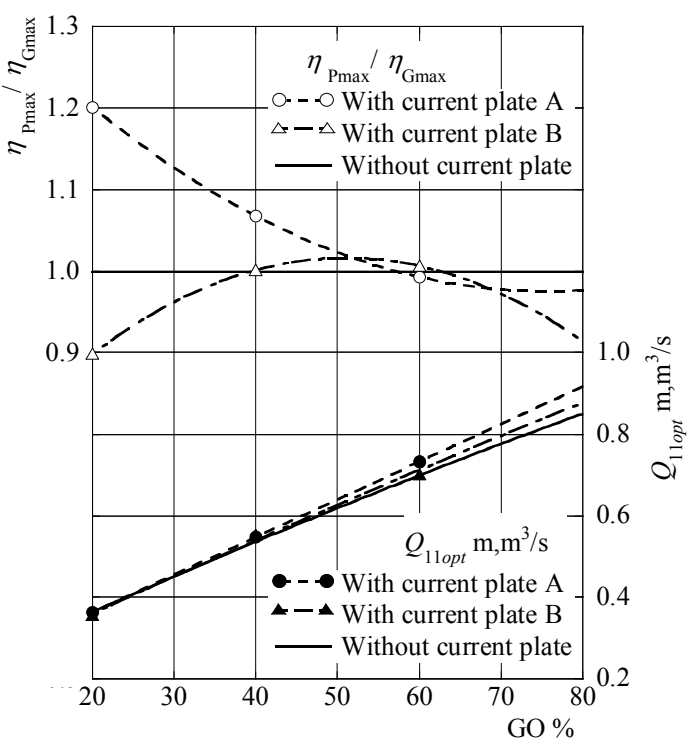

Figure 11. Efficiency improvement.

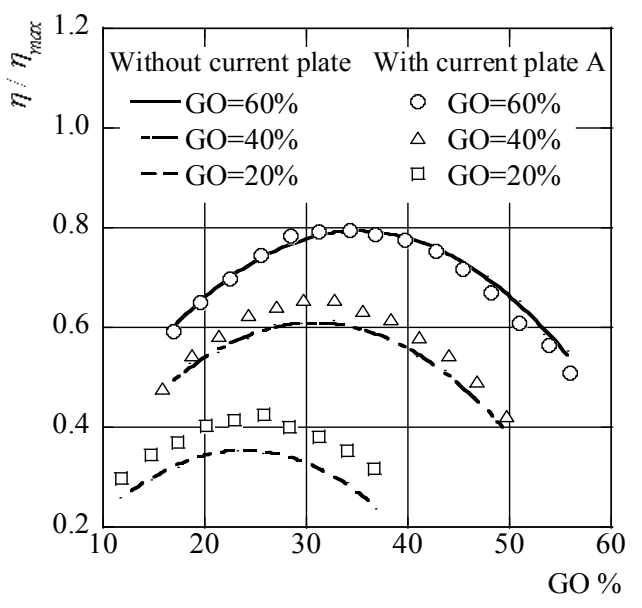

Figure 12. Hydraulic efficiency.

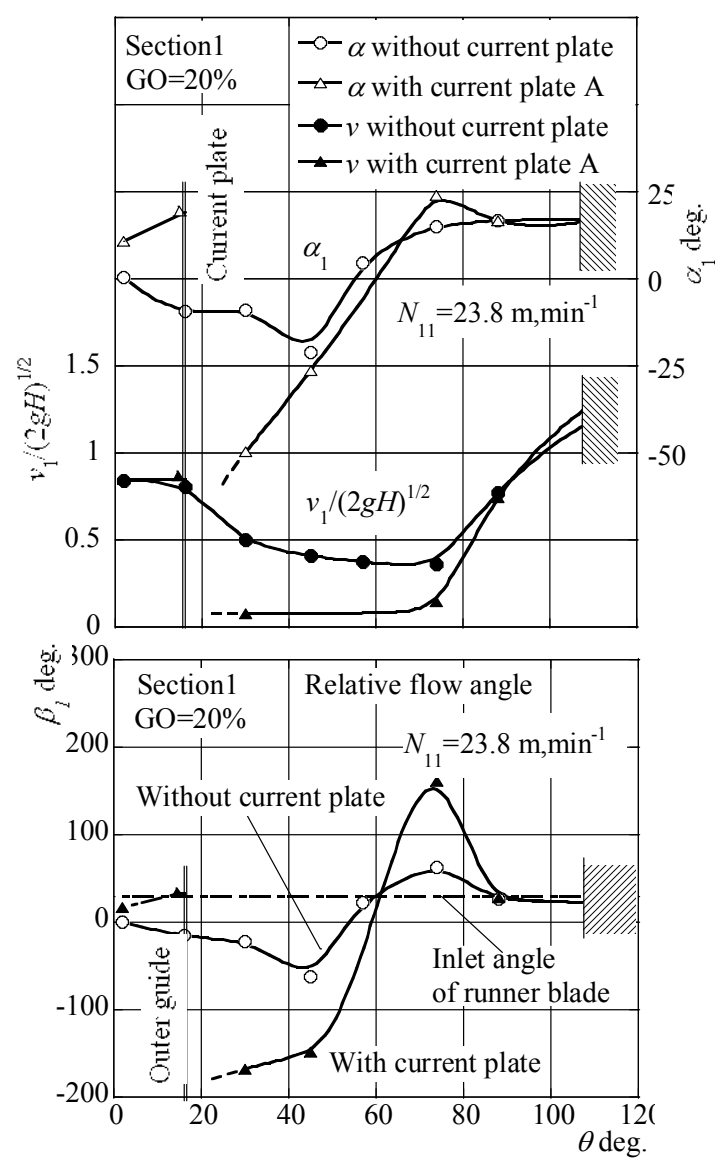

Figure 13. Effect of the current plate on flow conditions at Section 1.

the runner work owing to the slow velocity. On the contrary, the flow affects mainly the runner work in the region not only from $\theta=60$ to 109 but also from 0 to 15 degrees. The flow in the latter region at Section 1 discharges to Section 2 (see Figure 14), and improves conspicuously the runner work because the relative flow angle is reasonable (Figure 13). Improvement of the 
flow condition at Section 1 makes the flow discharge at the smaller central angle $\theta$ at Section 2, and makes the flow crossing in the runner reinter to the runner with nearly the same flow angle $\beta_{2}$ as $\mathrm{GO}=100 \%$ (see Figure 6(b)). The flow condition at Section 3 is also improved as shown in Figure 15, and the results may bring the decrease of the discharging loss.

\subsection{Power Fraction between Streamlines}

Figure 16 shows the effect of the current plate on the theoretical power fraction $\varepsilon$ defined at 2.4.4. The current plate improves $\varepsilon$ on streamline $\mathrm{S}_{1}$ to $\mathrm{S}_{4}$, by contribution of the flow through Sections from 1 to 2 . Figure 16 also shows $\eta_{\mathrm{s}}=P_{S T} / \rho g Q H$. The power is reasonably higher on $\mathrm{S}_{7}$ to $\mathrm{S}_{10}$. The current plate deteriorates $\varepsilon$ and $\eta_{\mathrm{s}}$ on $\mathrm{S}_{5}$ and $\mathrm{S}_{6}$, because the flow passing convex surface of the guide vane runs into the runner accompanying with de dead water behind the current plate.

\section{Conclusions}

The relation between the performance and flow condition

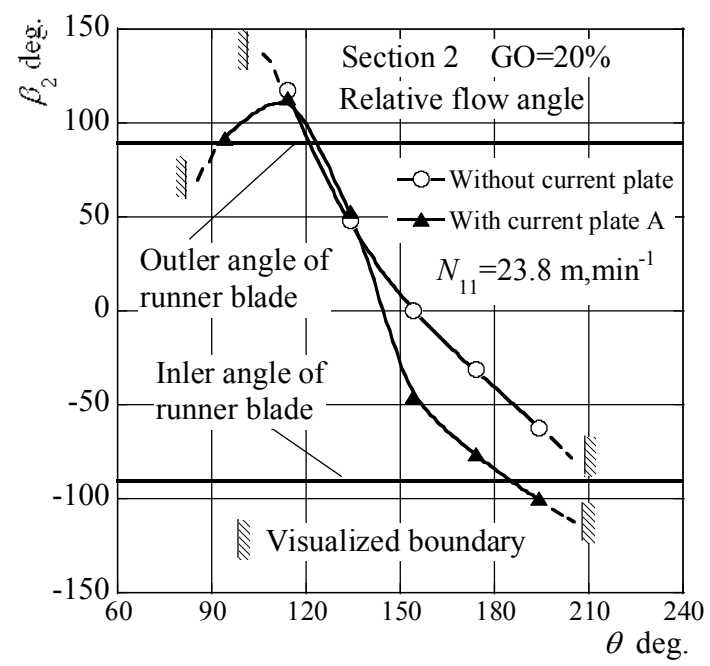

Figure 14. Effect of the current plate on the relative flow angle at Section 2.

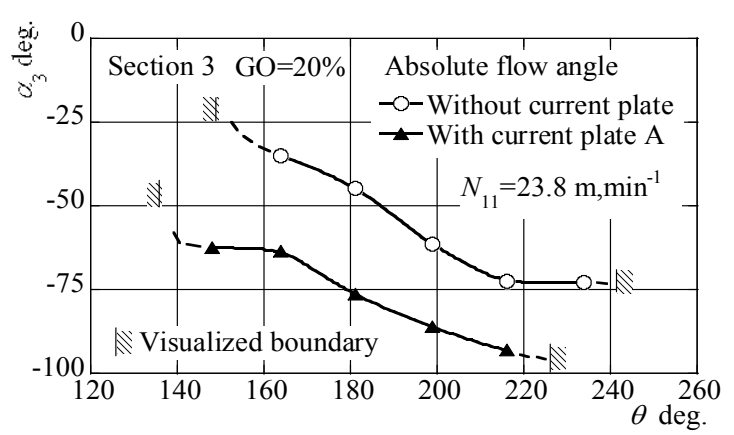

Figure 15. Effect of the current plate on the absolute angle at Section 3.

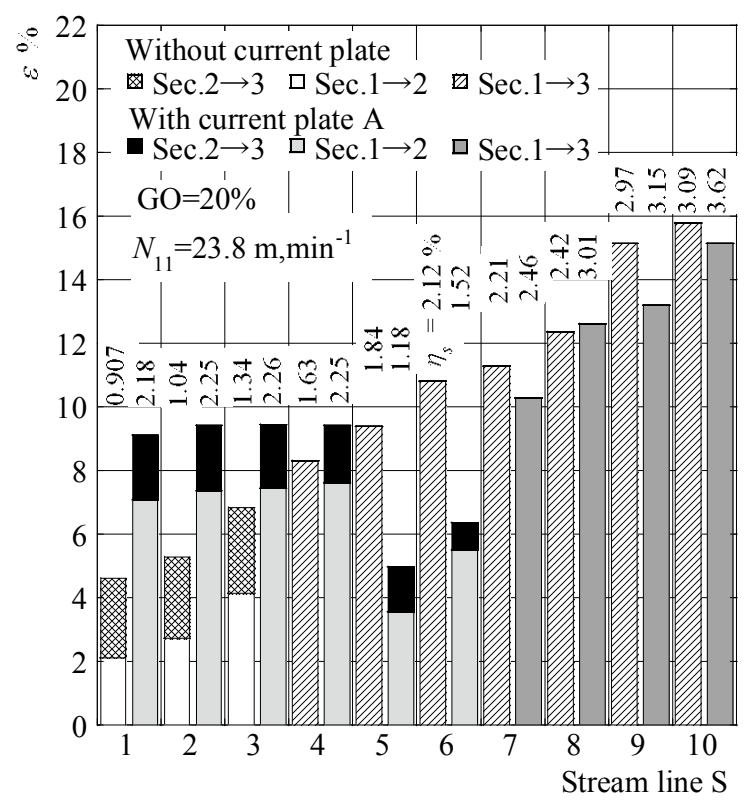

Figure 16. Effect on the current plate on the power fraction between streamlines.

was investigated experimentally with the model cross flow turbine in accordance with the traditional design, at the various operating conditions. Then, the hydraulic efficiency was improved in the low discharge adjusted by the guide vane equipped with the current plate. These are summarized as follows:

1) The flow condition in the inlet nozzle along the concave surface of the guide vane is poor in the lower discharge, and decreases the runner work.

2) The current plate installed at the concave surface of the guide vane contributes to improve the efficiency in the lower discharge.

\section{Acknowledgements}

The authors would like to deeply express their thanks to Prof. Young-Do Choi from Mokpo National University, Korea, for discussing the experimental results with the numerical simulations [12], and Mr. Hirotaka Honda for helping the experiments.

\section{REFERENCES}

[1] H. Kobayashi, "Small Capacity Hydropower," Water Culture, No. 39, 2011, p. 4. (in Japanese)

[2] L. Cho, K. Kurokawa, J. Matsui and H. Imamura, “Application of Low Head Cross Flow Turbine to Micro Capacity Hydropower (Simplified Structure and Improved Performances)," JSME Series B, Vol. 67, No. 664, 2001, pp. 222-227. (in Japanese)

[3] T. Toyokura, T. Kanemoto, T. Kitahora and A. Shiraisi, "Researches of Cross Flow Turbine," JSME Series B, Vol. 51, No. 461, 1985, pp. 143-151. (in Japanese) 
doi:10.1299/kikaib.51.143

[4] T. Kitahora, M. Inagaki, M. Uchida and S. Ooike, "Influence of Pressure in Runner Chamber on Performance Estimation of Micro-Head Cross Flow Hydraulic Turbine," Proceedings of Renewable Energy 2010, Yokohama, 31 May-2 June 2010, CD-ROM: O-Sh-4-5.

[5] Turbomachinery Society of Japan, "Hydro Turbine," Japan Industrial Publishing Co. Ltd., Tokyo, 1992, pp. 6567. (in Japanese)

[6] S. Croquer, M. Asuaje, J. de Andrade, F. Jeanty and J. Clarembaux, "Use of CFD Tools in Internal Deflector Design for Cross Flow Turbine Efficiency Improvement," Proceedings of ASME 2012 Fluids Engineering Summer Meeting, Rio Grande, 10 July 2012, CD-ROM: FEDSM 2012-72017.

[7] H. Olgun, "Effect of Interior Guide in Cross Flow Turbine Runner on Turbine Performance," International Journal of Energy Researches, Vol. 24, No. 11, 2000, pp. 953964.

doi:10.1002/1099-114X(200009)24:11<953::AID-ER634 $>3.0 . \mathrm{CO} ; 2-3$
[8] T. Toyokura and T. Kanemoto, "Cross Flow Turbine," Energy and Resource, Vol. 4, No. 3 1983, pp. 234-239. (in Japanese)

[9] Turbomachinery Society of Japan, "Hydro Turbine," Japan Industrial Publishing Co. Ltd., Tokyo, 1992, p. 78. (in Japanese)

[10] Turbomachinery Society of Japan, "Hydro Turbine," Japan Industrial Publishing Co. Ltd., Tokyo, 1992, p. 64. (in Japanese)

[11] K. Kokubu, K. Yamasaki, H. Hond and T. Kanemoto, "Effect of Inner Guide on Performances of Cross Flow Turbine," Proceedings of 26th IAHR Symposium on Hydraulic Machinery and System, Beijing, 19-23 August 2012, CD-ROM: IAHRXXVI-198.

[12] K. Kokubu, T. Kanemoto, S. Son and Y. Choi, "Performance Improvement of a Micro Eco Cross-Flow Hydro Turbine," Journal of the Korean Society of Marine Engineering, Vol. 36, No. 7, 2012, pp. 902-909. doi:10.5916/jkosme.2012.36.7.902 